\title{
Electroreduction of Carbon Dioxide by Heterogenized Cofacial Porphyrins
}

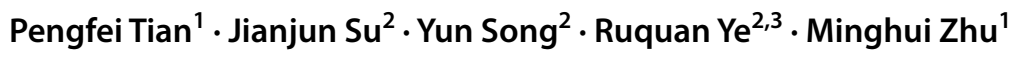

Received: 2 July 2021 / Revised: 12 July 2021 / Accepted: 16 July 2021 / Published online: 3 August 2021

(c) The Author(s) 2021

\begin{abstract}
Great attention has been paid to cofacial porphyrins due to their many unique advantages over their monomeric analogs. However, their synthesis is usually complicated. In this work, a facile impregnation method for preparing heterogenized, cofacially stacked porphyrins is proposed. An anionic porphyrin is introduced as an underlayer for immobilization of cationic cobalt porphyrin via electrostatic force. The metal center of the underlying molecule contributes to the electronic structure of the upper cationic cobalt porphyrin. Screening reveals the anionic iron porphyrin to be the most efficient underlayer molecule, lowering the activation energy barrier of $\mathrm{CO}_{2}$ electroreduction, with an improved turnover frequency by $74 \%$ to $8.0 \mathrm{~s}^{-1}$ at $-0.6 \mathrm{~V}$ versus RHE.
\end{abstract}

Keywords $\mathrm{CO}_{2} \mathrm{RR} \cdot$ Porphyrin $\cdot$ Cofacial $\cdot$ Heterogenization

\section{Introduction}

Metal porphyrins have received great attention as catalysts because of the clear molecular structures, which is beneficial for understanding the structure-activity relationships. Besides, the electronic structure of the catalytically active metal center, coordinated with four nitrogen atoms, could be effectively tuned by the surrounding ligands [1-4]. So far, there have been a variety of porphyrin-based molecular catalysts reported active for oxygen reduction reaction, oxygen evolution reaction, hydrogen evolution reaction, and $\mathrm{CO}_{2}$ electroreduction $\left(\mathrm{CO}_{2} \mathrm{RR}\right)$ [5-9].

Motivated by natural enzymes with dual metal centers, such as cytochrome $c$ oxidase and carbon monoxide

Ruquan Ye

ruquanye@cityu.edu.hk

$\triangle$ Minghui Zhu

minghuizhu@ecust.edu.cn

1 State Key Laboratory of Chemical Engineering, School of Chemical Engineering, East China University of Science and Technology, Shanghai 200237, China

2 State Key Laboratory of Marine Pollution, Department of Chemistry, City University of Hong Kong, Hong Kong 999077, China

3 City University of Hong Kong Shenzhen Research Institute, Shenzhen 518057, China dehydrogenase, much effort has been devoted to designing cofacial systems with two porphyrin units [10-14], probably because the presence of two metal centers can distribute the demands for redox and coordination numbers across two sites to favor reactions involving the multielectron transfer and a cofacial configuration could optimize the transition state energy level and therefore result in a more enhanced activity than their monomeric analogs [15]. In the past decade, the synthesis of numerous cofacial porphyrin catalysts has been reported for different reactions [16-21]. Taking the $\mathrm{CO}_{2} \mathrm{RR}$, an essential reaction to mitigate greenhouse $\mathrm{CO}_{2}$ emissions, as an example [22, 23]. Mohamed et al. [24] reported a cofacial iron tetraphenyl porphyrin (FeTPP) dimer for electrochemical $\mathrm{CO}_{2}$-to- $\mathrm{CO}$ reduction in $\mathrm{DMF} / \mathrm{H}_{2} \mathrm{O}$ solution, achieving high Faradaic efficiency (FE) of $95 \%$ and outstanding turnover frequency (TOF) number of $4300 \mathrm{~s}^{-1}$ at a moderate overpotential of $660 \mathrm{mV}$. They further assembled the cofacial molecule onto a fluorine-doped tin oxide electrode with a phosphonic acid anchor, showing high activity and stability for $\mathrm{CO}_{2} \mathrm{RR}$ in aqueous electrolytes [10]. Zahran et al. [25] demonstrated that the substituents on cofacial porphyrin rings greatly affected the catalysis process, and electron-donating groups such as mesityl could lead to increased TOF values. The concept of cofacial porphyrins has also been extended to fabricating the porous organic cage composed of six iron porphyrin units. The supramolecular catalyst produced $\mathrm{CO}$ 
with near-quantitative Faradaic efficiency, with activities reaching 55250 turnovers [26].

However, the synthesis of cofacial porphyrins usually involves a series of complicated procedures preventing their large-scale production. Herein, the neutral tetraphenyl porphyrin molecules are functionalized with cationic methylanilinium $\left(-\mathrm{N}\left(\mathrm{CH}_{3}\right)_{3}{ }^{+}\right)$and anionic sulfonate groups $\left(-\mathrm{SO}_{3}{ }^{-}\right)$ (Scheme 1), with the electrostatic interaction between these two substituents driving the self-assembly of the cofacial porphyrin system. Characterization measurements, electrochemical analysis, and density functional theory (DFT) calculations reveal a strong electronic interaction between the metal centers, significantly decreasing the reaction barrier and resulting in a more improved $\mathrm{CO}_{2} \mathrm{RR}$ performance.

\section{Experimental}

\section{Catalyst Synthesis}

Reduced graphene oxide (rGO, surface area $500 \mathrm{~m}^{2} / \mathrm{g}$ ) was purchased from Tokyo Chemical Industry Co., Ltd. and used as received. Cobalt tetra-(4- $N, N, N$-trimethylanilinium) porphyrin (CoTMAP), cobalt tetrasulfonatophenyl porphyrin tetrasodium (CoTSPP), iron tetrasulfonatophenyl porphyrin tetrasodium (FeTSPP), and nickel tetrasulfonatophenyl porphyrin tetrasodium (NiTSPP) were synthesized using a reported procedure [27]. Cofacial porphyrins supported on rGO were prepared by two-step incipient wetness impregnation (Fig. 1a). Briefly, CoTSPP (1.5 mg) was dissolved in deionized water and impregnated on rGO $(36.5 \mathrm{mg})$. The
Scheme 1 Molecular structures of a COTMAP and $\mathbf{b}$ CoTSPP

Fig. 1 a Two-step impregnation method to synthesize cofacial porphyrins supported on rGO. b TEM image, STEM image, and the corresponding EDX maps for $\mathrm{C}, \mathrm{Co}$, and $\mathrm{N}$ of the as-prepared $\mathrm{Co} / \mathrm{Co}$-Por catalyst. c XPS spectrum showing the Co $2 p_{3 / 2}$ signals and $\mathbf{d}$ UV-Vis spectra for CoTMAP, CoTSPP, and $\mathrm{Co} / \mathrm{Co}$-Por

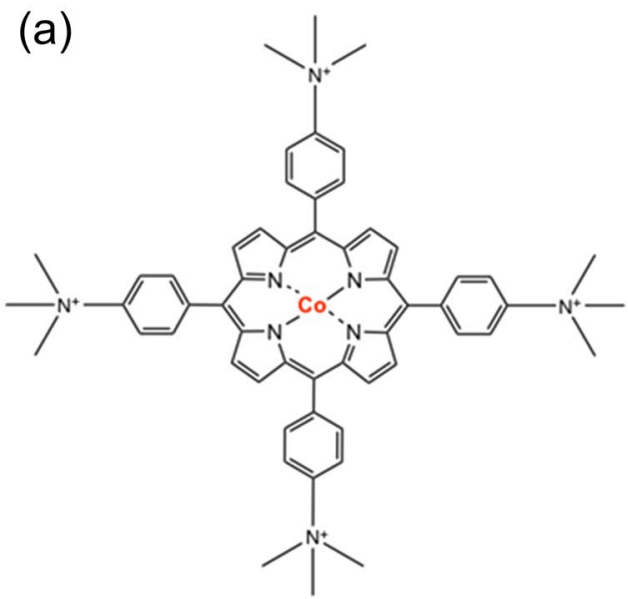

(b)

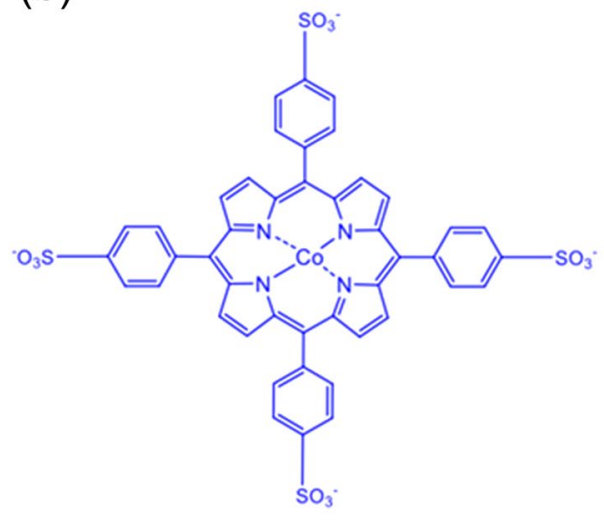

(a)

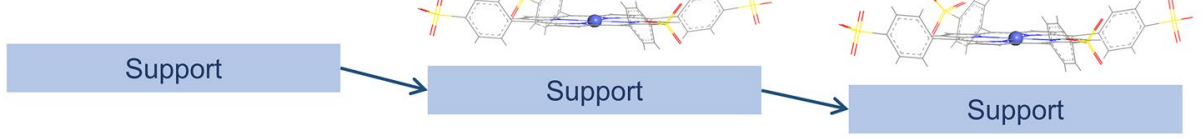

(b)

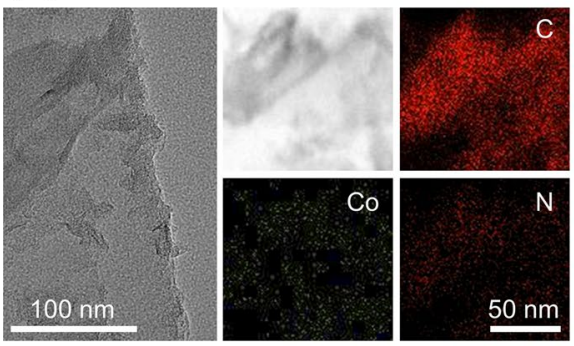

(c)

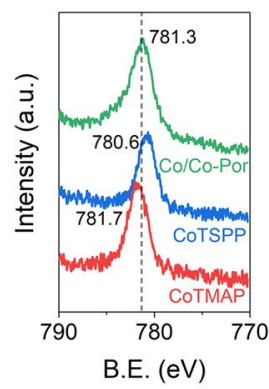

(d)

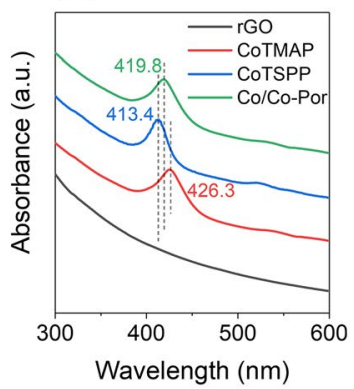


mixture was aged for $12 \mathrm{~h}$ followed by vacuum drying at $80{ }^{\circ} \mathrm{C}$ overnight. A second impregnation step was then conducted to further impregnate CoTMAP ( $2 \mathrm{mg}$ ). Again, a 12-h aging step was performed to allow a sufficient interaction between the CoTMAP and CoTSPP molecules. The resulting catalyst, denoted as $\mathrm{Co} / \mathrm{Co}$-Por, was eventually dried in a vacuum oven at $80{ }^{\circ} \mathrm{C}$ overnight. The same procedures were also done to prepare the Ni/Co-Por and Fe/Co-Por catalysts, but using NiTSPP and FeTSPP, respectively, in the first impregnation step. Inductively coupled plasma-atomic emission spectroscopy (ICP-OES) was carried out to calculate the actual Co contents in $\mathrm{Co} / \mathrm{Co}-\mathrm{Por}, \mathrm{Ni} / \mathrm{Co}-\mathrm{Por}$, and $\mathrm{Fe} /$ Co-Por of $0.51 \%, 0.24 \%$, and $0.26 \%$, respectively, which are close to their nominal values.

\section{Catalyst Characterizations}

ICP measurements were conducted using an Agilent 725 ICP-OES. Catalyst morphology was analyzed using a JEOL JEM-2100F field emission source transmission electron microscope (TEM) operating at $200 \mathrm{kV}$. X-ray photoelectron spectroscopy (XPS) analysis was obtained using a Thermo ESCALAB 250Xi spectrometer equipped with a monochromatic AlK radiation source $(1486.6 \mathrm{eV}$, pass energy $20.0 \mathrm{eV}$ ). The diffuse reflectance UV-Vis spectrum was recorded in the $200-800 \mathrm{~nm}$ range using a UV-Vis spectrophotometer (Lambda 750, PerkinElmer, Inc.).

\section{Electrochemical Measurements}

To prepare the working electrode, the catalyst powder $(5 \mathrm{mg}$ ) and Nafion solution ( $13 \mu \mathrm{L}, 5 \mathrm{wt} \%$, Sigma-Aldrich) were dispersed in ethanol ( $1 \mathrm{~mL}$, Aladdin, ACS, $\geq 99.5 \%)$ and sonicated for $1 \mathrm{~h}$ to form a uniform catalyst ink. Then, the ink was drop cast onto carbon paper (Toray, TGP-H-060) to reach a catalyst loading of $0.1 \mathrm{mg} / \mathrm{cm}^{2}$. Its electrochemical performance in $\mathrm{CO}_{2}$ reduction was tested in a customized H-cell separated by a Nafion 117 membrane. Platinum foil and a leak-free $\mathrm{Ag} / \mathrm{AgCl}$ electrode (LF-2, Innovative Instrument Inc.) were used as the counter and reference electrodes, respectively. Before the experiments, sodium bicarbonate $(1.75 \mathrm{~mL}, 0.5 \mathrm{M}$, Sigma-Aldrich, $\geq 99.5 \%)$ solution was injected into the working and counter compartments. $\mathrm{CO}_{2}$ was purged into the chambers for $10 \mathrm{~min}$ before electrochemical polarization. Electrochemical responses were recorded by a CHI650E potentiostat. Electrolyte resistance between the reference and working electrodes was measured by potential electrochemical impedance spectroscopy and manually compensated. During the electrolysis, gas products were analyzed using an online gas chromatograph equipped with a Hayesep-D column, TCD detector, and FID detector.

The Faradaic efficiencies of gas products were calculated using the following equation:
$\mathrm{FE}_{i}=\frac{\frac{v \cdot x}{22400 \times 60} \cdot n \cdot F}{I}$

where $i$ represents $\mathrm{CO}$ or $\mathrm{H}_{2} ; x$ is the concentration of $\mathrm{CO}$ or $\mathrm{H}_{2} ; \nu$ is the feeding rate of $\mathrm{CO}_{2} ; n$ is the electron transfer number (2, for both $\mathrm{CO}$ and $\mathrm{H}_{2}$ ); $F$ is the Faradaic constant $(96,485 \mathrm{C} / \mathrm{mol})$; and $I$ is the average current during electrolysis.

\section{Theoretical Calculation}

DFT calculations were performed using the Gaussian09 at the PBE0 level using the LanL2DZ basis set [28-31] for metal atoms $(\mathrm{Fe}, \mathrm{Co}$, and $\mathrm{Ni}$ ) and 6-31G(d) basis set for non-metal atoms $(\mathrm{H}, \mathrm{N}, \mathrm{C}, \mathrm{O}$, and $\mathrm{S})$.

\section{Results and Discussion}

Incipient wetness impregnation can allow anionic porphyrins to uniformly immobilize onto the rGO support through $\pi-\pi$ interactions and sufficient interaction between the cationic porphyrins and anionic ones through electrostatic force. Figure $1 \mathrm{~b}$ shows the TEM image of the as-prepared $\mathrm{Co} / \mathrm{Co}-$ Por catalyst with a clean two-dimensional morphology. The energy-dispersive X-ray spectroscopy (EDS) maps also show the uniform distribution of $\mathrm{C}, \mathrm{N}$, and $\mathrm{Co}$ and no apparent aggregates. To verify, we also prepared the hybrid catalyst at a high loading by impregnating $15 \mathrm{mg}$ of CoTSPP on $35 \mathrm{mg}$ of rGO. The resulting catalyst shows many porphyrin aggregates with an estimated average size of 5-10 nm (Fig. S1). From this perspective, a low porphyrin loading, which requires a dilute porphyrin-water solution for impregnation, is key to the successful preparation of the highly dispersed hybrid catalysts.

XPS and UV-Vis spectroscopy were performed to study the electronic structure of Co/Co-Por. Figure $1 \mathrm{c}$ shows the XPS Co $2 p$ spectrum showing Co $2 p_{3 / 2}$ peaks at 781.7 and $780.6 \mathrm{eV}$ for CoTMAP and CoTSPP, respectively. The different binding energies of the Co $2 p_{3 / 2}$ band are due to the distinct electronegativity features of the peripheral functionalities. The electron-withdrawing methylanilinium group decreases the electron density around the Co center, while the electron-donating sulfonate group increases the electron density around cobalt [27]. The two-porphyrin cofacial $\mathrm{Co} / \mathrm{Co}$-Por reveals a neutralized binding energy value of $781.3 \mathrm{eV}$ for the Co $2 \mathrm{p}_{3 / 2}$ signal, indicating the electrons within the stacked molecule system to be significantly redistributed, as confirmed by the shifted Soret band for Co/CoPor $(419.8 \mathrm{~nm})$ as compared to CoTMAP $(426.3 \mathrm{~nm})$ or CoTSPP (413.4 nm) (Fig. 1d). The Q bands for all three samples could hardly be distinguished from the strong background 
of rGO absorbance. The above results reveal the intimate contact between the CoTMAP and CoTSPP molecules.

$\mathrm{Ni} / \mathrm{Co}-\mathrm{Por}$ and $\mathrm{Fe} / \mathrm{Co}$-Por were also prepared by introducing NiTSPP and FeTSPP as the sublayer porphyrins, respectively, for systematically investigating the structure-activity relationship of cofacial porphyrins during the electrochemical $\mathrm{CO}_{2}$ reduction. For comparison, monomeric CoTMAP, CoTSPP, FeTSPP, and NiTSPP catalysts on rGO were also prepared at a content of $5 \mathrm{wt} \%$. The EDS maps in Fig. S2 confirm the highly disperse NiTSPP and CoTMAP in Ni/ Co-Por and uniform distribution of FeTSPP and CoTMAP in $\mathrm{Fe} / \mathrm{Co}$-Por. In addition, the binding energies of the Co $2 \mathrm{p}_{3 / 2}$ signal are also found to shift in these two catalysts due to the electronic interactions (Fig. S3). The steady-state electroreduction of $\mathrm{CO}_{2}$ was conducted in a customized $\mathrm{H}$-cell in a $\mathrm{CO}_{2}$-saturated $0.5 \mathrm{M} \mathrm{NaHCO}_{3}$ electrolyte. Cyclic voltammetry measurements show prominent reduction currents at potentials more negative than approximately $-0.4 \mathrm{~V}$ versus RHE (Fig. S4). CoTMAP exhibits a stable current at a potential of $-0.6 \mathrm{~V}$ versus RHE with an average current density of $4.6 \mathrm{~mA} / \mathrm{cm}^{2}$ during $1 \mathrm{~h}$ of electrolysis (Fig. 2a, Fig. S5). Moreover, the activities for cofacial porphyrins follow the order Fe/Co-Por $\left(8.0 \mathrm{~mA} / \mathrm{cm}^{2}\right)>\mathrm{Co} / \mathrm{Co}-\mathrm{Por}(6.5 \mathrm{~mA} /$ $\left.\mathrm{cm}^{2}\right)>\mathrm{Ni} / \mathrm{Co}$-Por $\left(5.7 \mathrm{~mA} / \mathrm{cm}^{2}\right)$. Current densities are much lower in the sulfonate group functionalized metal porphyrin than in the methylanilinium group functionalized CoTMAP catalyst. CoTSPP, NiTSPP, and FeTSPP have overall current densities of $1.4,0.7$, and $1.1 \mathrm{~mA} / \mathrm{cm}^{2}$, respectively, at $-0.6 \mathrm{~V}$ versus RHE (Fig. S6), in agreement with our previous study that $\mathrm{CO}_{2}$ reduction favors cationic substituents over neutral or anionic ones [27]. Excellent selectivities toward CO production are shown by all tested catalysts, with $\mathrm{FE}_{\mathrm{CO}}$ values over $90 \%$ (Fig. 2b, Fig. S7).

The resistances of the catalysts were investigated by AC impedance analysis at an open-circuit voltage (OCV). The Nyquist plots demonstrate that the four samples have similar interfacial charge transfer resistance $\left(R_{\mathrm{ct}}\right)$, possibly due to the identical and low catalyst loading. TOF values were calculated for investigating the intrinsic reactivity of each catalyst based on the number of CoTMAP molecules on the top layer. It could be argued that the underlying MTSPP may not be completely stacked (i.e., covered) and may still contribute to the reductive currents. Therefore, a set of H/Co-Por samples were prepared as a control with various $\mathrm{H}_{2}$ TMAP loadings for the second impregnation step. As described above, CoTSPP alone delivers a $j_{\mathrm{CO}}$ of $1.3 \mathrm{~mA} / \mathrm{cm}^{2}$ (Fig. 2c). The introduction of $\mathrm{H}_{2}$ TMAP, which is inactive for $\mathrm{CO}$ production, suppresses the current densities. This serves as direct proof that the cationic porphyrins preferentially graft on the pre-deposited anionic porphyrins by electrostatic force and block the underlying metal centers from accessing the reactants. The partial current density of $\mathrm{CO}$ becomes negligible
Fig. 2 a Overall current densities and $\mathbf{b}$ Faradaic efficiencies of $\mathrm{CO}$ and $\mathrm{H}_{2}$ over CoTMAP and cofacial porphyrins. $\mathbf{c}$ The partial current density of $\mathrm{CO}$ $\left(j_{\mathrm{CO}}\right)$ over cofacial porphyrin containing CoTSPP and $\mathrm{H}_{2}$ TMAP with different weight ratios. d Calculated $\mathrm{TOF}_{\mathrm{CO}}$ values for CoTMAP and cofacial porphyrin catalysts (reaction was performed at $-0.6 \mathrm{~V}$ versus RHE in a $\mathrm{CO}_{2}$-saturated $0.5 \mathrm{M}$ $\mathrm{NaHCO}_{3}$ electrolyte) (a)
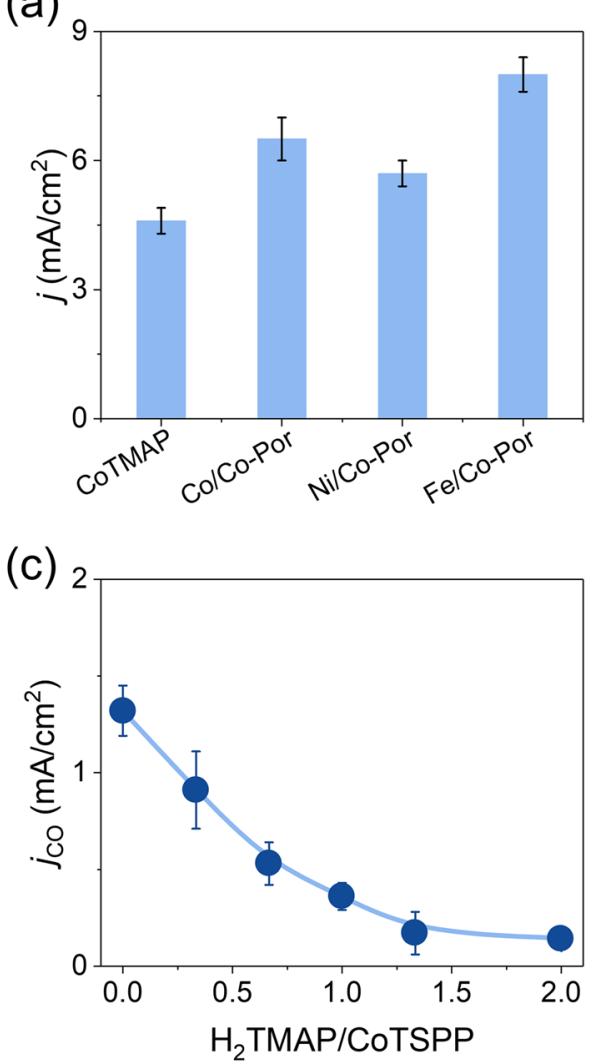

(b)

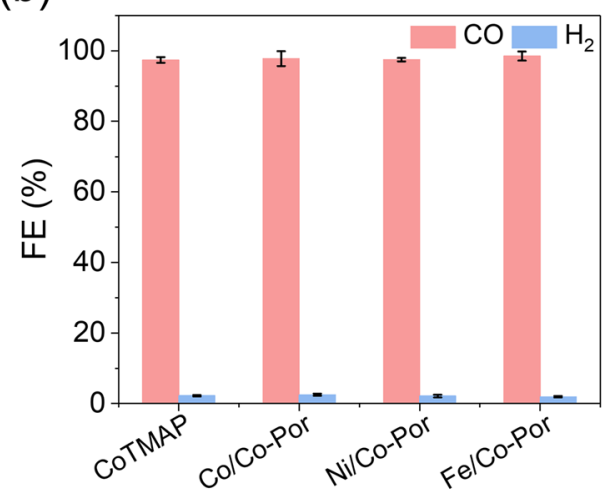

(d)

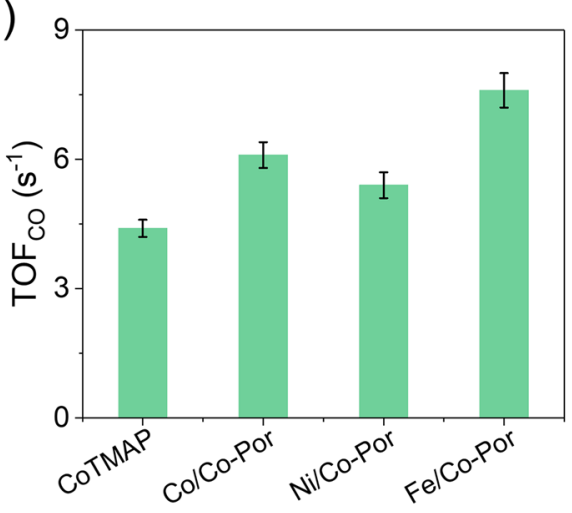


Fig. 3 a Optimized structures for $\mathrm{Co} / \mathrm{Co}$-Por with adsorbed $* \mathrm{COOH}$ and $* \mathrm{CO}$ as well as free-standing $\mathrm{CO}_{(\mathrm{g})}$. b Free energy diagrams for $\mathrm{CO}$ production on CoTMAP, $\mathrm{Co} / \mathrm{Co}-\mathrm{Por}$, $\mathrm{Ni} / \mathrm{Co}-\mathrm{Por}$, and $\mathrm{Fe} / \mathrm{Co}$-Por. c The plot of $\log (\mathrm{TOF})$ against the theoretical overpotential values showing a linear correlation

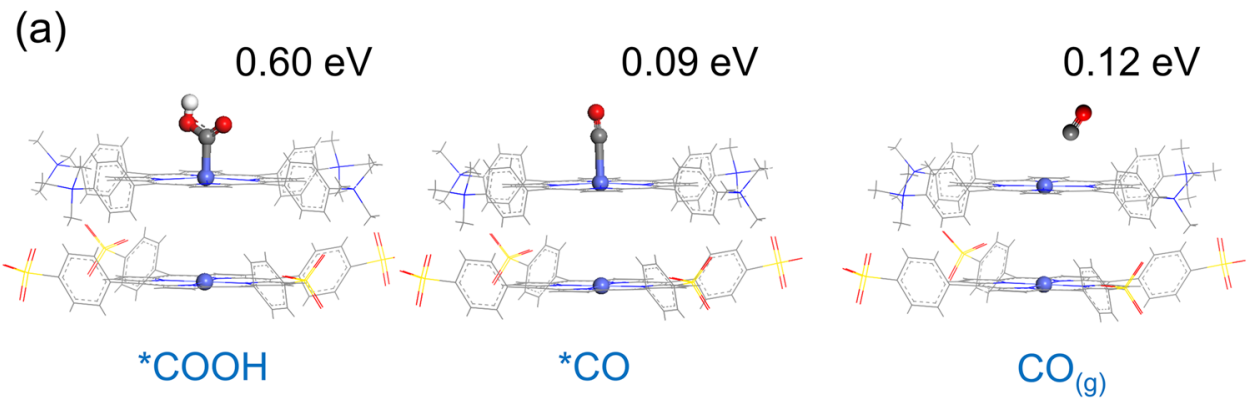

(b)

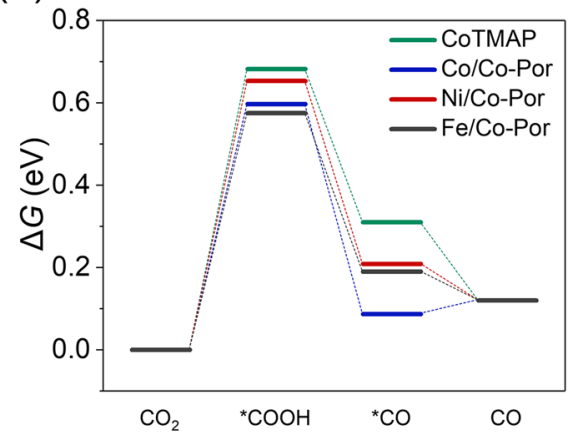

(c)

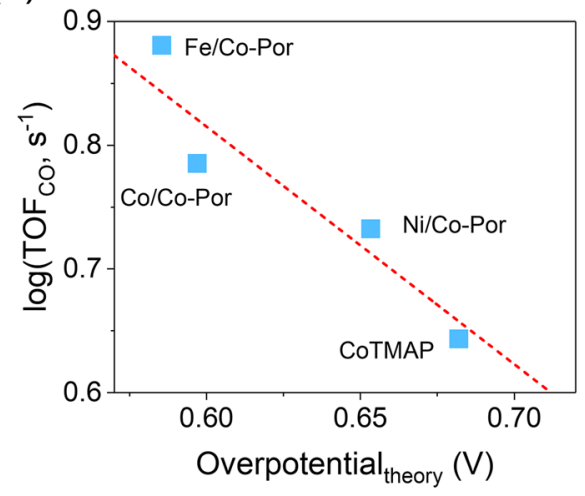

$\left(<10 \%\right.$ of the original value) with weight ratios of $\mathrm{H}_{2} \mathrm{TMAP} /$ CoTSPP over 1.3, implying the complete assembly of H/CoPor cofacial porphyrin. The control experiment also validates our calculation protocol of TOF values for the samples discussed here. The CoTMAP catalyst exhibits a $\mathrm{TOF}_{\mathrm{CO}}$ of $4.4 \mathrm{~s}^{-1}$ (Fig. 2d), similar to that of Ref. [27]. Fabricating the cofacial porphyrins using MTSPP leads to improved intrinsic activities with the order of $\mathrm{Fe} / \mathrm{Co}$-Por $\left(7.6 \mathrm{~s}^{-1}\right)>\mathrm{Co} / \mathrm{Co}$-Por $\left(6.1 \mathrm{~s}^{-1}\right)>\mathrm{Ni} / \mathrm{Co}-\mathrm{Por}\left(5.4 \mathrm{~s}^{-1}\right)$.

DFT calculations were performed for analyzing the thermochemical reaction energetics of $\mathrm{CO}_{2} \mathrm{RR}$ on CoTMAP, $\mathrm{Co} /$ Co-Por, Ni/Co-Por, and Fe/Co-Por. The molecular structures were first optimized for the cofacial porphyrins according to the $\mathrm{H}$-aggregation configuration. The introduced $\mathrm{H}_{2}$ TMAP blocked the underlying metal sites (Fig. 2c), which implies a high overlapping degree (Fig. S8). $\mathrm{CO}_{2}$-to-CO electroreduction by molecular catalysts involves $* \mathrm{COOH}$ and * $\mathrm{CO}$ intermediates [32-34]. * $\mathrm{COOH}$ formation is usually considered the rate-determining step (RDS), and the * $\mathrm{CO}$ species are believed to desorb promptly to form the $\mathrm{CO}$ products. CoTMAP, Co/Co-Por, Ni/Co-Por, and Fe/Co-Por have Tafel slopes of $114.9,123.8,118.4$, and $133.7 \mathrm{mV} / \mathrm{dec}$ (Fig. S9). Furthermore, a $\mathrm{CO}_{2}$ reaction order of approximately 1 is determined for all the catalysts, indicating the $\mathrm{CO}_{2}$-to- ${ }^{*} \mathrm{COOH}$ transformation to be the rate-limiting step (Fig. S10)[9]. * $\mathrm{COOH}$ formation is the most energy-demanding, as suggested by the DFT results, associated with the highest energy barrier of $+0.6 \mathrm{eV}$ compared to other reaction steps (Fig. 3a). Figure $3 b$ shows the free energy diagrams for all CoTMAP-based catalysts. While all the cofacial porphyrins show the same $\mathrm{RDS}$ for $\mathrm{CO}_{2}$-to-CO conversion as the monomeric CoTMAP, their reaction energy barriers appear to be lower (Fig. S11). Then, the calculated theoretical reaction overpotentials over the tested catalysts follow the order Fe/Co-Por $(0.58 \mathrm{~V})<\mathrm{Co} / \mathrm{Co}-\mathrm{Por}(0.60 \mathrm{~V})<\mathrm{Ni} / \mathrm{Co}$-Por $(0.65 \mathrm{~V})<$ CoTMAP $(0.68 \mathrm{~V})$. The above results show that, in addition to peripheral substituents, metal atoms from the underlying catalytically inactive porphyrin molecules also play an important role in tuning the electronic structure of the catalytically active porphyrin molecules on the top layer. Correspondingly, the $\log (\mathrm{TOF})$ values appear to be linearly correlated with the theoretical overpotential values.

\section{Conclusions}

In summary, a two-step impregnation method is proposed to prepare cofacially stacked porphyrins by utilizing the electrostatic force between the cationic and anionic porphyrin molecules, which not only avoids the common tedious chemical synthesis route but also effectively tunes the electronic structure of the molecular catalysts, eventually leading to a lower reaction energy barrier and a significantly improved reaction rate for $\mathrm{CO}_{2}$ electroreduction. Our method should theoretically be adaptable to other carbonaceous supports such as carbon black and carbon nanotubes. In addition, the facile approach has the potential to guide the rational design of other cofacial porphyrin catalysts. 
Supplementary Information The online version contains supplementary material available at https://doi.org/10.1007/s12209-021-00305-8.

Acknowledgements This work was sponsored by the Program for Professor of Special Appointment (Eastern Scholar) at Shanghai Institutions of Higher Learning and Shanghai Sailing Program (No. 19YF1410600). R.Y. acknowledge the Young Scientists Fund of the National Natural Science Foundation of China (No. 21905240) and the State Key Laboratory of Marine Pollution (SKLMP) Seed Collaborative Research Fund.

\section{Declarations}

Conflict of interest The authors declare that there is no conflict of interest.

Open Access This article is licensed under a Creative Commons Attribution 4.0 International License, which permits use, sharing, adaptation, distribution and reproduction in any medium or format, as long as you give appropriate credit to the original author(s) and the source, provide a link to the Creative Commons licence, and indicate if changes were made. The images or other third party material in this article are included in the article's Creative Commons licence, unless indicated otherwise in a credit line to the material. If material is not included in the article's Creative Commons licence and your intended use is not permitted by statutory regulation or exceeds the permitted use, you will need to obtain permission directly from the copyright holder. To view a copy of this licence, visit http://creativecommons.org/licenses/by/4.0/.

\section{References}

1. Manbeck GF, Fujita E (2015) A review of iron and cobalt porphyrins, phthalocyanines and related complexes for electrochemical and photochemical reduction of carbon dioxide. J Porphyrins Phthalocyanines 19(1-3):45-64

2. Sun CF, Gobetto R, Nervi C (2016) Recent advances in catalytic $\mathrm{CO}_{2}$ reduction by organometal complexes anchored on modified electrodes. New J Chem 40(7):5656-5661

3. Elouarzaki K, Kannan V, Jose V et al (2019) Recent trends, benchmarking, and challenges of electrochemical reduction of $\mathrm{CO}_{2}$ by molecular catalysts. Adv Energy Mater 9(24):1900090

4. Birdja YY, Pérez-Gallent E, Figueiredo MC et al (2019) Advances and challenges in understanding the electrocatalytic conversion of carbon dioxide to fuels. Nat Energy 4(9):732-745

5. Choi J, Kim J, Wagner P et al (2019) Energy efficient electrochemical reduction of $\mathrm{CO}_{2}$ to $\mathrm{CO}$ using a three-dimensional porphyrin/ graphene hydrogel. Energy Environ Sci 2:747-755

6. Hu XM, Rønne MH, Pedersen SU et al (2017) Enhanced catalytic activity of cobalt porphyrin in $\mathrm{CO}_{2}$ electroreduction upon immobilization on carbon materials. Angew Chem Int Ed 56(23):6468-6472

7. Tatin A, Comminges C, Kokoh B et al (2016) Efficient electrolyzer for $\mathrm{CO}_{2}$ splitting in neutral water using earth-abundant materials. Proc Natl Acad Sci 113(20):5526-5529

8. Zion N, Friedman A, Levy N et al (2018) Bioinspired electrocatalysis of oxygen reduction reaction in fuel cells using molecular catalysts. Adv Mater 30(41):1800406

9. Zhu M, Chen J, Huang L et al (2019) Covalently grafting cobalt porphyrin onto carbon nanotubes for efficient $\mathrm{CO}_{2}$ electroreduction. Angew Chem Int Ed Engl 58(20):6595-6599

10. Mohamed EA, Zahran ZN, Naruta Y (2017) Efficient heterogeneous $\mathrm{CO}_{2}$ to $\mathrm{CO}$ conversion with a phosphonic acid fabricated cofacial iron porphyrin dimer. Chem Mater 29(17):7140-7150
11. Guilard R, Brandes S, Tardieux C et al (1995) Synthesis and characterization of cofacial metallodiporphyrins involving cobalt and Lewis acid metals: new dinuclear multielectron redox catalysts of dioxygen reduction. J Am Chem Soc 117(47):11721-11729

12. Peljo P, Murtomäki L, Kallio T et al (2012) Biomimetic oxygen reduction by cofacial porphyrins at a liquid-liquid interface. J Am Chem Soc 134(13):5974-5984

13. Takai A, Gros CP, Barbe JM et al (2009) Enhanced electron-transfer properties of cofacial porphyrin dimers through $\pi-\pi$ interactions. Chemistry 15(13):3110-3122

14. Collman JP, Kim K, Leidner CR (1987) Synthesis, characterization, and electrochemistry of novel diruthenium cofacial porphyrin dimers. Inorg Chem 26(7):1152-1157

15. Oldacre AN, Friedman AE, Cook TR (2017) A self-assembled cofacial cobalt porphyrin prism for oxygen reduction catalysis. J Am Chem Soc 139(4):1424-1427

16. Collman JP, Denisevich P, Konai Y et al (1980) Electrode catalysis of the four-electron reduction of oxygen to water by dicobalt faceto-face porphyrins. J Am Chem Soc 102(19):6027-6036

17. Collman JP, Bencosme CS, Durand RR Jr et al (1983) Mixed-metal face-to-face porphyrin dimers. J Am Chem Soc 105(9):2699-2703

18. Durand RR, Bencosme CS, Collman JP et al (1983) Mechanistic aspects of the catalytic reduction of dioxygen by cofacial metalloporphyrins. J Am Chem Soc 105(9):2710-2718

19. Nakamura T, Ube H, Shionoya M (2013) Silver-mediated formation of a cofacial porphyrin dimer with the ability to intercalate aromatic molecules. Angew Chem Int Ed Engl 52(46):12096-12100

20. Oliveri CG, Heo J, Nguyen ST et al (2007) A convergent coordination chemistry-based approach to dissymmetric macrocyclic cofacial porphyrin complexes. Inorg Chem 46(19):7716-7718

21. Suijkerbuijk BMJM, Tooke DM, Spek AL et al (2007) Onedimensional, cofacial porphyrin polymers formed by self-assembly of meso-tetrakis(ERE donor) zinc(II) porphyrins. Chem Asian J 2(7):889-903

22. Hepburn C, Adlen E, Beddington J et al (2019) The technological and economic prospects for $\mathrm{CO}_{2}$ utilization and removal. Nature 575(7781):87-97

23. Gruber N, Clement D, Carter BR et al (2019) The oceanic sink for anthropogenic $\mathrm{CO}_{2}$ from 1994 to 2007. Science 363(6432):1193-1199

24. Mohamed EA, Zahran ZN, Naruta Y (2015) Efficient electrocatalytic $\mathrm{CO}_{2}$ reduction with a molecular cofacial iron porphyrin dimer. Chem Commun Camb Engl 51(95):16900-16903

25. Zahran ZN, Mohamed EA, Naruta Y (2016) Bio-inspired cofacial Fe porphyrin dimers for efficient electrocatalytic $\mathrm{CO}_{2}$ to $\mathrm{CO}$ conversion: overpotential tuning by substituents at the porphyrin rings. Sci Rep 6:24533

26. Smith PT, Benke BP, Cao Z et al (2018) Iron porphyrins embedded into a supramolecular porous organic cage for electrochemical $\mathrm{CO}_{2}$ reduction in water. Angew Chem 130(31):9832-9836

27. Zhu MH, Yang DT, Ye RQ et al (2019) Inductive and electrostatic effects on cobalt porphyrins for heterogeneous electrocatalytic carbon dioxide reduction. Catal Sci Technol 9(4):974-980

28. Adamo C, Barone V (1999) Toward reliable density functional methods without adjustable parameters: the PBE0 model. J Chem Phys 110(13):6158-6170

29. Hay PJ, Wadt WR (1985) Ab initio effective core potentials for molecular calculations: potentials for the transition metal atoms Sc to Hg. J Chem Phys 82(1):270-283

30. Wadt WR, Hay PJ (1985) Ab initio effective core potentials for molecular calculations: potentials for main group elements $\mathrm{Na}$ to Bi. J Chem Phys 82(1):284-298

31. Hay PJ, Wadt WR (1985) Ab initio effective core potentials for molecular calculations: potentials for $\mathrm{K}$ to $\mathrm{Au}$ including the outermost core orbitals. J Chem Phys 82(1):299-310 
32. Lin S, Diercks CS, Zhang YB et al (2015) Covalent organic frameworks comprising cobalt porphyrins for catalytic $\mathrm{CO}_{2}$ reduction in water. Science 349(6253):1208-1213

33. Costentin C, Drouet S, Robert M et al (2012) A local proton source enhances $\mathrm{CO}_{2}$ electroreduction to $\mathrm{CO}$ by a molecular $\mathrm{Fe}$ catalyst. Science 338(6103):90-94

34. Zhu MH, Ye RQ, Jin K et al (2018) Elucidating the reactivity and mechanism of $\mathrm{CO}_{2}$ electroreduction at highly dispersed cobalt phthalocyanine. ACS Energy Lett 3(6):1381-1386

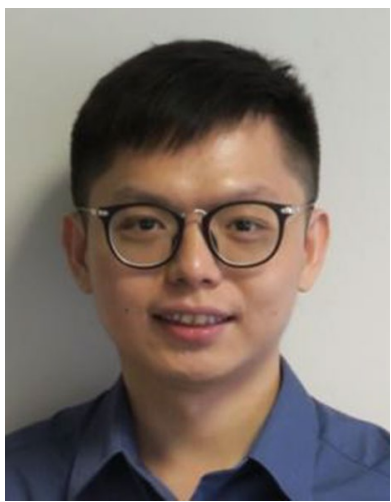

Ruquan Ye is an assistant professor in Chemistry, City University of Hong Kong. He received his B.S. (Chemistry) in 2012 from Hong Kong University of Science and Technology under Prof. Ben Zhong Tang's supervision, and his Ph.D. (chemistry) in 2017 from Rice University mentored by Prof. James M. Tour. He was a postdoctoral associate in Chemical Engineering at the Massachusetts Institute of
Technology (2017-2018). His research interests include the development of cost-effect methods for materials manufacturing and the investigation of their applications.

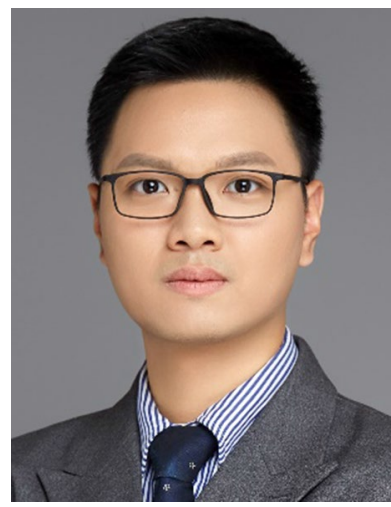

Minghui Zhu obtained his Ph.D. degree in 2016 from Lehigh University under the supervision of Prof. Israel E. Wachs. After spending one year and a half working as a postdoctoral associate with Prof. Karthish Manthiram at the Massachusetts Institute of Technology, he joined the East China University of Science and Technology as a Professor in 2018. His research interests mainly focus on the development of new heterogeneous catalysts for $\mathrm{C} 1$ chemistry. 